\title{
人工弁の血流特性からみた単独僧帽弁置換後の 血栓塞栓症の発生率と重症度
}

\author{
今村栄三郎* 石原 茂樹* 筒井 達夫* 青崎 正彦** \\ 長村 好章** 今井 康晴* 橋本 明政* 小柳 仁*
}

\section{Incidence and severity of thromboembolism following isolated mitral valve replacement; Comparison of various valve prostheses}

\begin{abstract}
Eisaburo IMAMURA*, Shigeki ISHIHARA*, Tatsuo TSUTSUI*, Masahiko AOSAKI**, Yoshiaki OSAMURA**, Yasuharu IMAI*, Akimasa HASHIMOTO* and Hitoshi KOYANAGI*
\end{abstract}

Key words: Starr-Edwards ball valve, SAM valve, tilting disc valve, porcine bioprosthesis, flow characteristics

Incidence and severity of thromboembolism (T. E.) associated with various types of valve prostheses were surveyed. A total of 576 patients who survived 1 month or longer after isolated mitral valve replacement was divided into three groups depending on flow characteristics of valve prosthesis implanted: Group I had the lateral flow type valves, such as Starr-Edwards ball valve and SAM valve (85 cases); Group II had semi-central flow type valves of tilting disc prostheses (345 cases) and Group III had central flow type valve of porcine bioprostheses (146 cases). Severity of T. E. was classified as follows; $\mathrm{I}^{\circ}$ when symptoms were improved within 1 month after onset, $\mathrm{II}^{\circ}$ when they persisted 1 month or longer, and $\mathrm{III}^{\circ}$ when T. E. caused fatality. T. E. occurred in 40 patients among the 576 operative survivors (6.9\%). Incidence was highest in group I $(16 / 85,18.8 \% ; 2.9 \% /$ patient-year). By contrast, both of groups II and III showed equally low incidence; that is, $16 / 345,4.6 \% ; 1.2 \% / \mathrm{pt}-\mathrm{yr}$ in group II and $11 / 146,7.5 \% ; 1.8 \% / \mathrm{pt}-\mathrm{yr}$ in group III. Prognosis of T. E. was poorest in group $\mathrm{I}$ in which 8 patients showed $\mathrm{II}^{\circ}$ and the remaining 8 were

* 東京女子医科大学付属日本心臓血圧研究所外科 [干162 新宿区河田町 10], Department of Cardiovascular Surgery, The Heart Institute of Japan, Tokyo Women's Medical College, Tokyo, Japan.

** 同 内科, Department of Cardiology, The Heart Institute of Japan, Tokyo Women's Medical College, Tokyo, Japan. 
in III $^{\circ}$. Symptoms and prognosis of T. E. were milder in group III than in group II. None of the group III was subjected to fatal cerebral embolism, while two patients of group II were lost due to massive brain infarction.

These results suggest that the flow characteristics of the valve prosthesis is importantly involved not only in incidence but also in severity of thromboembolism following mitral valve replacement.

\section{はじめに}

血栓塞栓症は人工弁置換後にみられる重篤な 合併症である. 症状と予後は一様ではなく軽度 一過性のものから，ながく片側マヒ症状を残寸 もの,さらに広汎な脳梗塞を生じて死の転带を とるものまで, 塞栓部位括よび血栓子の新旧大 小に応じてさまざまな病態を呈する。抗血栓性 能にすぐれた材質の開発，デザインの改良さら に抗凝固剤の配合の工夫など本症を予防するた めの努力が精力的に拉こなわれている.なかで も構造意匠，すなわら人工弁固有の血流特性が 本症の発生率敊よび重症度にどの程度かかわっ
ているかを単独僧帽弁置換（MVR）症例を基 に検討した。

\section{I. 対 象}

1964年 5 月から 1982 年 7 月までの 19 年間に 643例が単独僧帽并置換をうけた。術後早期 (30 日以内）に死亡した 67例を除く576例に対し問 診またはアンケート調查を扣こなった。

対象患者を使用人工弁の血流特性に和就じて 3 群に分ける. 図 1 に示すように, I 群：側方 流型の Starr-Edwards ボール弁やSAM 弁（垂 直運動ディスク弁）の置換をらけたもの（85 例)，II群：準中心流型の 傾斜ディスク弁置換

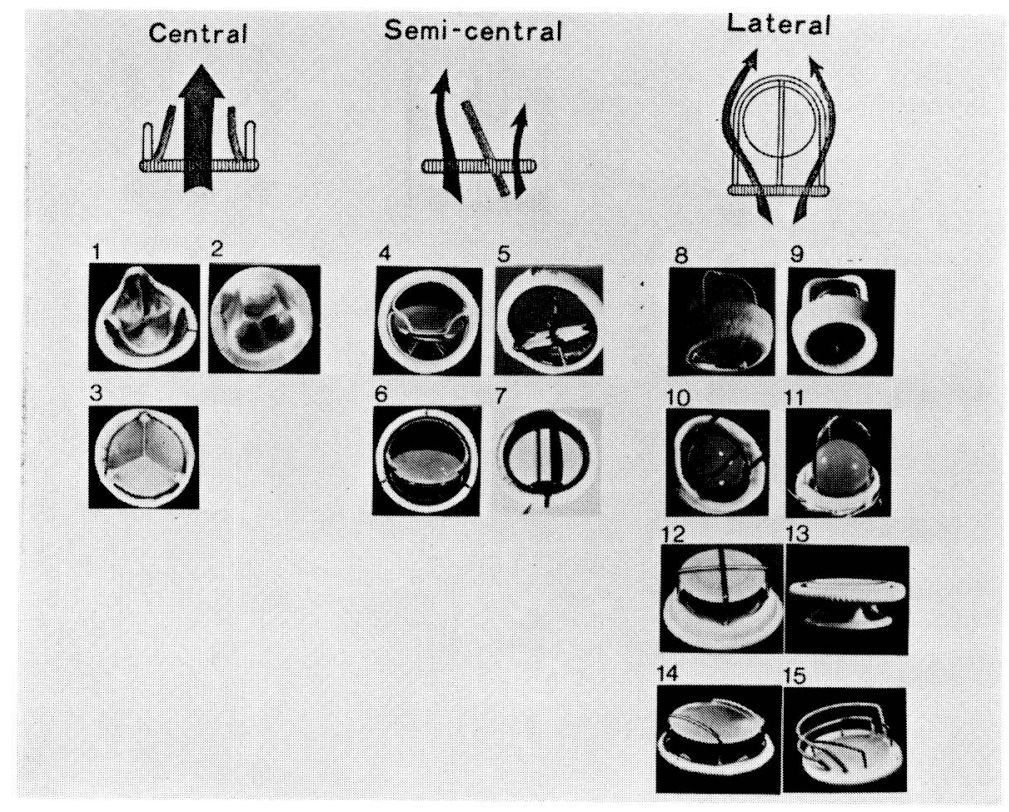

Fig. 1: Three different types of valve prostheses divided according to flow characteristics. 


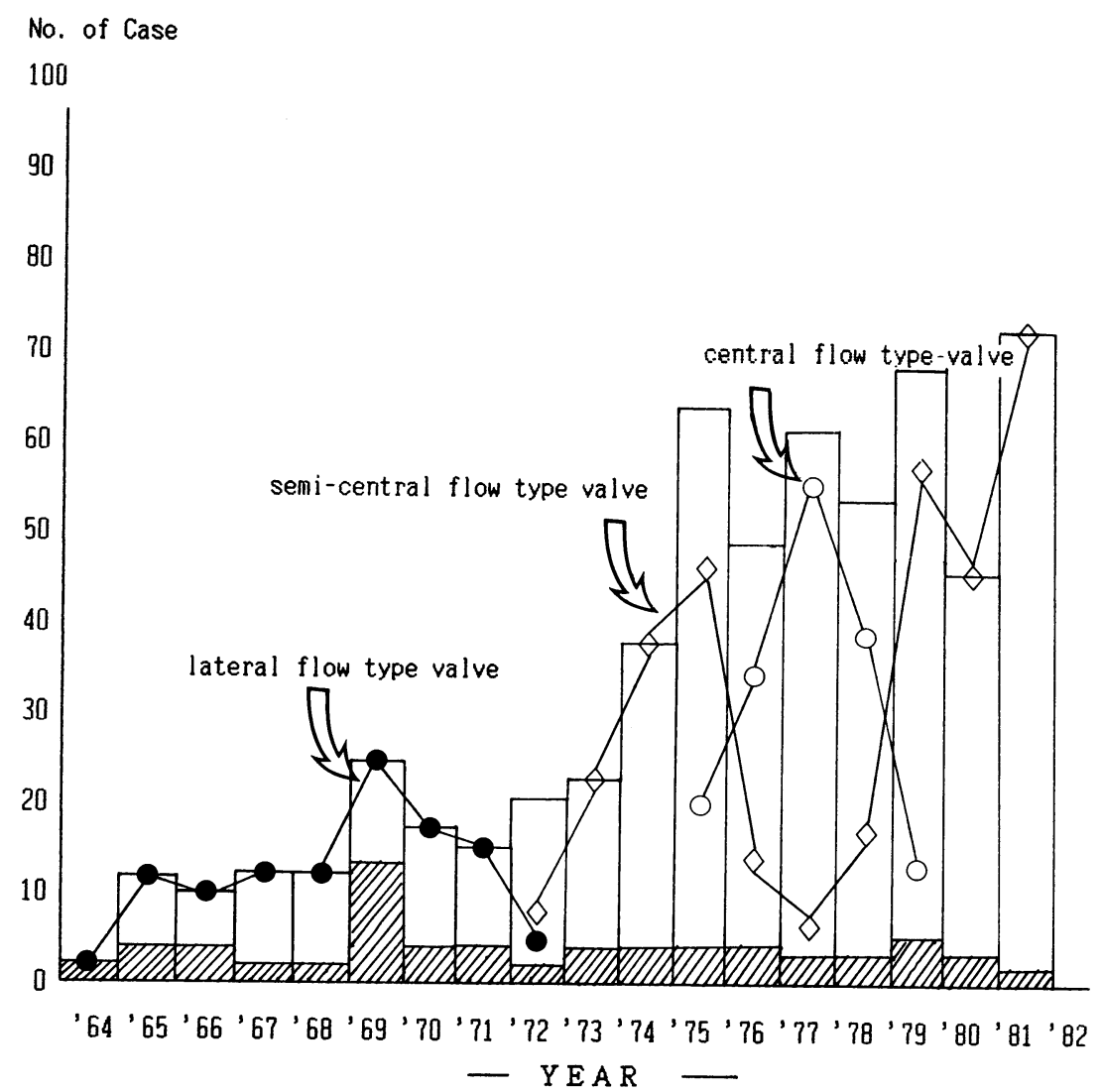

Fig. 2: Graphs showing number of patients undergoing isolated mitral valve replacement. Shaded portions illustrate number of operative deaths. Solid lines indicated by arrows show number of valve prostheses used in each chronological year.

(345例)， III群 : 中心流型の 異種生体弁置換症 例（146例） となる. 術後追跡期間は I 群557 年, II 群1283年, III群624年, 計 2,464 年で平均

\section{3年になる.}

図 2 に年度別僧帽弁置換症例数と機種別人工 弁使用個数を揭げる：Starr-Edwards 弁 12, SAM 弁73, Björk-Shiley 弁161, SJM 弁150, Omni-Science 弁26, Hall-Kaster 弁 8, Hancock 弁107, Carpentier-Edwards 弁15, AngellShiley 弁24個. 初期は側方流型人工弁, 70 年 代は準中心流型と中心流型の併用, そして80年 以降は準中心流型が多く使用されている.

抗凝固療法は生体弁置換群の少数例をのぞ き，原則として恒久的ワーファリン投与を扣こ なった. 術後第 2 病日より開始し，トロンボテ スト10〜25\%を至適量とした。また症例に扮沶 じ適時抗血小板剤を併用した。

\section{II. 結 果}

僧帽弁置換後 1 か月以上生存した576例中 6.9 \%にあたる40例が計43回の血栓塞栓症を発症し た.これは $1.7 \% /$ patient-year (患者年百分率) に相当する. 40例中37例に心房細動がみられ, 8 例が同時心内手術（三尖弁輪形成術 5 例，大 動脈弁形成術 2 例, 心室中隔欠損閉鎖術 2 例, $\mathrm{AC}$ バィパス術 1 例）をらけていた.

左房内血栓 2 例, そして術前に血栓塞栓症の 既往を有するもの 2 例であった。

表 1 に人工弁機種別にみた血栓塞栓症の発症 率を示す. I 群がもっとも多く 85 例中 16 回 (18.8\%) で，2.9\%/pt-yrになる.これに対し II 群と III群は I 群に比べ有意に $(\mathrm{p}<0.001)$ 低 い. II 群は345例中16回 (4.6\%) であり， 1.2 \%/pt-yr となる。III群は146例中11回 (7.5\%), 
Table 1: Incidence of Thromboembolism Following Mitral Valve Replacement

\begin{tabular}{|c|c|c|c|c|c|c|}
\hline \multirow{2}{*}{ Group } & \multirow[b]{2}{*}{ Prostheses } & \multirow{2}{*}{$\begin{array}{l}\text { operative } \\
\text { survivors }\end{array}$} & \multicolumn{4}{|c|}{ Incidence Rate } \\
\hline & & & No. pt & frequency & $(\%)$ & $\% / \mathrm{pt}-\mathrm{yr}$ \\
\hline \multirow[t]{3}{*}{$\mathrm{I}$} & Starr-Edwards ball valve & 12 & 4 & 4 & 33.3 & 4.0 \\
\hline & SAM valve & 73 & 11 & 12 & 16.4 & 2.6 \\
\hline & subtotal & 85 & 15 & 16 & 18.8 & 2.9 \\
\hline \multirow[t]{5}{*}{ II } & Björk-Shiley valve & 161 & 7 & 7 & 4.3 & 0.7 \\
\hline & SJM valve & 150 & 9 & 9 & 1.0 & 3.0 \\
\hline & Omni Science valve & 26 & 0 & 0 & 0 & 0 \\
\hline & Hall-Kaster valve & 8 & 0 & 0 & 0 & 0 \\
\hline & subtotal & 345 & 16 & 16 & 4.6 & 1.2 \\
\hline \multirow[t]{5}{*}{ III } & Hancock valve & 107 & 8 & 9 & 8.4 & 1.9 \\
\hline & Angell-Shiley valve & 24 & 0 & 0 & 0 & 0 \\
\hline & Carpentier-Edwards valve & 15 & 1 & 2 & 13.3 & 2.5 \\
\hline & subtotal & 146 & 9 & 11 & 7.5 & 1.8 \\
\hline & Total & 576 & 40 & 43 & 7.5 & 1.7 \\
\hline
\end{tabular}

$1.8 \% / \mathrm{pt}-\mathrm{yr}$ であった. 準中心流型器械弁の 方 が中心流型の生体弁よりむしろ低い合併率をし めしたが，統計学的に有意な差はない（p> $0.1)$.

術後血栓塞栓症を合併した40例の症状をみる と, 半身不随 (手足の脱力感, シビレ感をふく む) 26例, 一過性の意識障害25例, 言語障害23 例, 脳梗塞 9 例, 視力障害 3 例, 四肢塞栓症 3 例, その他 2 例をみとめた. 重症度を予後の立 場からつぎの 3 度に分類した. I 度 : 症状が 1 か月以内にほとんど消失したもの. II度：なん らかのマヒ症状が 1 か月以上残存しているも の. III度 : 直接または間接の原因となって死の 転帰をとったもの.

図 3 に人工弁機種別にみた血栓塞栓症の重症 度と術後発症までの期間を示す. 重症度は発症 率に比例してI群（側方流型）がもっとも重篤 であった. 軽症一過性のものはなく,16回の発 症中 8 回は II 度, 他の 8 回はIII度で死の原因と なったＩII群とIII群を比較した場合, 発症率と は並行せず, 発症率の高いIII群の方がより軽症 傾向をしめした.

つまり，II群の16回中10回が II 度以上（うち 2 回がIII度）であったのに対し， III群にIII度は なく, 11 回中 5 回が I 度, 6 回が II 度の症状に とどまっている.

発症時期は術後比較的早い時期に集中してい
るのが目立つ. 不明 3 例を除く 40 回の発症のう ちほぼ半数の 18 回が術後 6 か月以内に抗こって いる. 1 年以上経過例では術後 10 年まで均等な 発症分布があり，とくに好発時期はみとめな い.

\section{III. 考察}

血栓塞栓症を臨床的に診断するのは必ずしも 容易ではない1). とくに非定型的な脳神経症状 の場合, 他の病因と混同したり, あるいは逆に 見落とすこともありらる。塞栓部位によって は, たとえば，遠隔期に和ける冠動脈への塞栓 は原因不明の急死としてあつかわれるのが普通 である2、。したがって, 実際の頻度は報告され ている頻度より若干多めと推定される.

本症の重症度が千差万別である以上，合併頻 度の比較だけではどのタイプの代用弁が最も危 険が少ないかを論ずることは妥当性を欠く。一 過性の症状のみで特別の治療を要しないもの と，長期にわたってマヒ症状をのこしたり死亡 原因となる大なる塞栓症では臨床的な意味合い が異なる，そこで重症度は従来提唱3)されてい る症状の種類または塞栓部位別ではなく, 予後 の立場から眺めるほうがより合理的である.

人工弁の血栓形成の三大要因として, 材料の 表面特性, 弁上下の血流特性および患者個人の 血液凝固機能特性があげられる．なかでも血流 


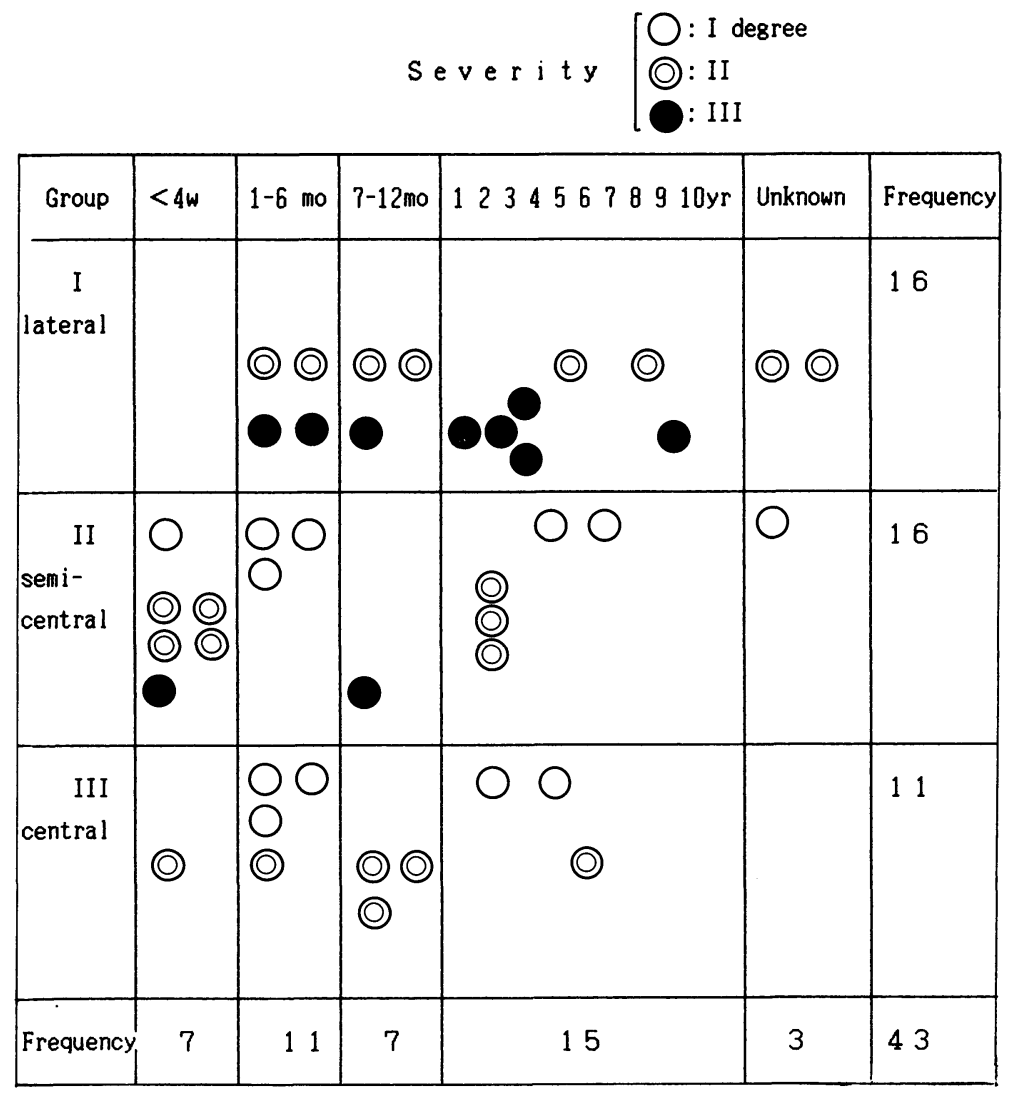

Fig. 3: Severity of thromboembolism is defined as $I^{\circ}$ when symptoms disappeared within 1 month of onset, $\mathrm{II}^{\circ}$ when persisted 1 month or longer, and $\mathrm{III}^{\circ}$ when embolism caused mortality.

性は基本的に弁の可動部分の構造に依存してい る. 中心流をさまたげる構造のものは乱流や血 流のうっ滞を生じて血栓をつくりやすい. した がって, 側方流型の人工弁に血栓形成率が高

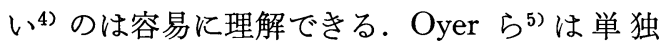
僧帽弁置換後の 血栓塞栓症の合 併率 は StarrEdwards 弁 10.9\%/pt-yr にたいし 異種生体弁 4. 1\%/pt-yr と大差があることを報告している. 他方，傾斜型ディスク弁と生体弁とを比較する と，文献上でも両者ほとんど差がみられない。 扮扮むね 1 ～4\%/pt-yrの範囲にある(16)7).

ただし Conpans ら ${ }^{8)}$ は傾斜型ディスク弁の一 種である Björk-Shiley 弁の僧帽弁置換後224例 中 19 例 $(8.5 \%)$ といら高率で血栓弁に因る死 亡があったことを報告して括り，血栓予防には 人工弁の適正な選択のほかに抗凝固療法の綿密 な組立てが重要であることを強調している，と くに心房細動, 左房内血栓, 巨大左房, 術前塞
栓症の既往 ${ }^{910}$ 10) 有する症例には coumadin (ワ ーファリン) のほかに dipyridamole（ペルサン チン), ticlopedine (パナルジン), aspirin 等 の血小板抑制剤招よび clofibrate（アモトリー ル）の併用が推奖される.

人工弁縫合部に仮性内膜が完成するのに約 6 か月を要する11)。この間，テフロン縫合輪部へ の血栓付着が起こりやすい. 多くの著者は術後 1 年以内の発症が高いこと, なかでも Oyer $ら^{12)}$ は生体弁置換後 3 か月以内の早期発症が50 \%を超えると報告している，以上の理由から， 抗凝固療法は可及的早期に開始すること，そし て少なくとも半年間は出血傾向に留意しつつ, きめこまかく強力に行う必要がある.

\section{結 論}

1. 人工弁置換後の血栓塞栓症は人工弁固有の 血流特性が合併頻度だけでなく，予後からみ 


\section{特た重症度に深く関与している。}

2. 頻度は側方流型 $>$ 中心流型 $>$ 準中心流型の 順に多い.人工弁の種類にかかわりなく術後 6 か月以内の早期発症が半数近くを占める.

3. 重症度は重い方から側方流型 $>$ 準中心流 型>中心流型であった，中心流特性を有する 異種生体弁は現在のところ, 血栓塞栓症に関 するかぎりもっとも安全な代用心蔵弁である といえる.

\section{文献}

1) Dale, J. : Arterial thromboemolic complications in patients with Björk-Shiley and LilleheiKaster tilting disc prostheses. Am. Heart J., 93; 715 722, 1977.

2) Edmunds, L.H.,Jr.: Thromboembolic complications of current cardiac valvular prostheses. Ann. Thorac. Surg., 34; 96 106, 1982.

3) Vidne,B.,Erdman,S. and Levy, M.J.: Thromboem bolism following heart valve replacement by prostheses: Survey among 365 consecutive patients. Chest, 63; 713 717, 1973.

4) Moggio, R.A., Hammond,G.L.,Stansel,H.C.,Jr., and Glenn,W.W.L.: Incidence of emboli with closth-covered Starr-Edwards valve without anticoagulation and with varing forms of anticoagulation. J. Thorac. Cardiovasc. Surg., 75; 296 299, 1978.

5) Oyer,P.E., Stinson,E.B., Griepp,R.B., and Shumway, N.E.: Valve replacement with Starr-
Edwards and Hancock prostheses. Ann. Surg., 186; 30 1 309, 1977.

6) Edmiston, W.A., Harrison, E.C., Duick, G.F., Parnassus, W. and Lau, F.Y.K. : Thromboe mbolismin mitral porcine valve recipients.

Am. J. Cardiol., 41; 508 511, 1978.

7) Jamieson,W.R.E., Janusz, M.T., Miyagishima, R.T., Munro, A.I.,et al. : Embolic complications of porcine heterograft cardiac valves. J.Thorac. Cardiovasc. Surg., 81; 626 631, 1981.

8) Copans, H., Lakier, J.B., Kinsley, R.H., Colsen, P.R.,Fritz,V.U.and Barlow, J.B. :Thrombosed Björk-Shiley mitral prostheses. Circulation, 61; $169 \sim 174,1980$.

9) Geha, A.S., Hammond, G.L., Laks., H, Stansel, H.C. and Glenn, W.L. : Factors affecting perfo$\mathrm{rm}$ ance and thromboembolism after porcine xenograft cardiac valve replacement. J. Thorac. Cardiovasc. Surg., 83; 377 384, 1982.

10) Hill. J.D., LaFollette,L., Szarnicki,R.J.,Avery, G.J.II., Wilson,R.M., Gerbode,F., Kerth,W.J., and Rodvien, R.: Risk-benefit analysis of warfar in therapy in Hancock mitral valve replacement. J. Thorac. Cardiovasc. Surg., 83; 718 723, 1982.

11）今村栄三郎：人工血管拉よびパッチ材料(楖原イ チ: 心蔵外科学), 南江堂, 東京, 1975, p. 176.

12) Oyer,P.E.,Stinson,E.B., Reitz,B.A, et al. : Long. term evaluation of the porcine xenograft bioprosthesis. J. Thorac. Cardiovasc. Surg., 78; 343 350, 1979.

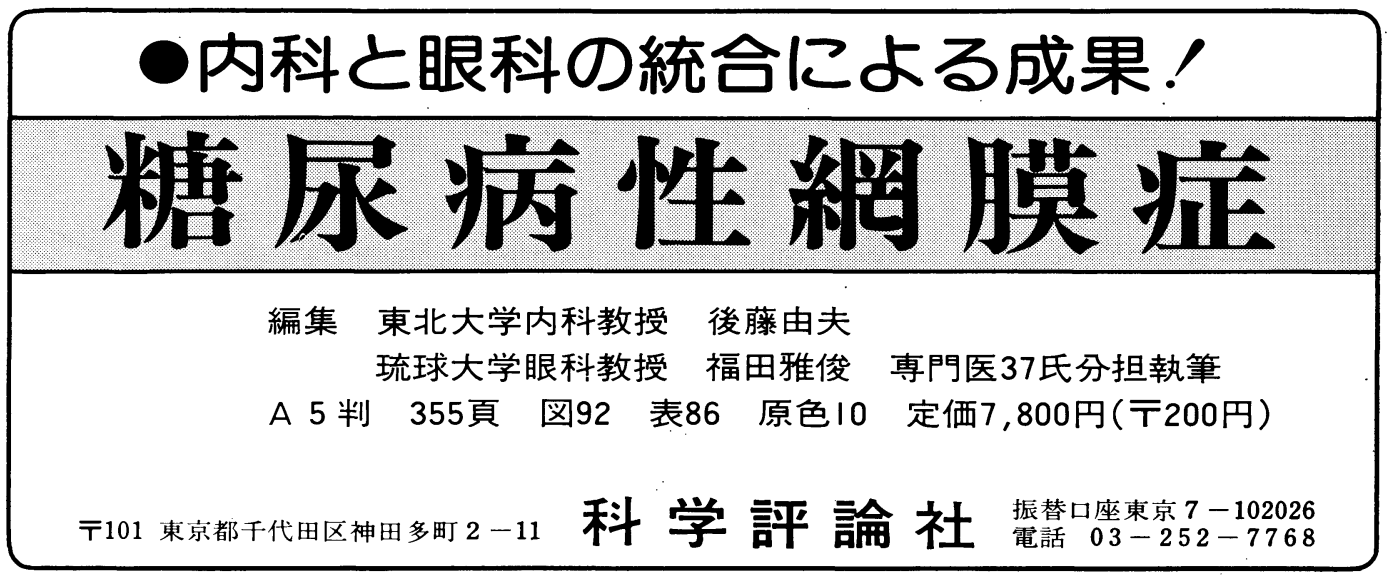

